\title{
NOTE \\ Internal Medicine \\ Clinical application of $2.16 \%$ hypertonic saline solution to correct the blood sodium concentration in diarrheic calves with hyponatremia
}

\author{
Mitsuhide NAKAGAWA ${ }^{1)}$, Kenji TSUKANO2), Yoshiki MURAKAMI'), \\ Marina OTSUKA ${ }^{2)}$, Kazuyuki SUZUKI')* and Hiroetsu SUZUKI') \\ ${ }^{1)}$ Hokushin Veterinary Medical Center, Nagano Prefectural Federation of Agricultural Mutual Aid Association, \\ 1-4-28 Miyoshicho, Nagano, Nagano 383-0025, Japan \\ 2)School of Veterinary Medicine, Rakuno Gakuen University, 582 Midorimachi, Bunnkyoudai, Ebetsu, \\ Hokkaido 069-8501, Japan \\ ${ }^{3)}$ School of Veterinary Medicine, Nippon Veterinary and Life Science University, 1-7-1 Kyounancho, Musashino, \\ Tokyo 180-0023, Japan
}

J. Vet. Med. Sci.

82(11): 1585-1588, 2020

doi: 10.1292/jvms.20-0286

Received: 13 May 2020

Accepted: 28 August 2020

Advanced Epub:

14 September 2020
ABSTRACT. The aim of this study was to examine whether $2.16 \%$ hypertonic saline solution (HSS) is useful for the treatment of diarrheic calves with hyponatremia. Eleven of 13 female Holstein calves exhibiting moderate diarrhea and hyponatremia received $1,250 \mathrm{~m} /$ of $2.16 \%$ HSS over 15 min regardless of body weight. The remaining two calves that were unable to stand and had severe hyponatremia received $2,500 \mathrm{~m} /$ of $2.16 \% \mathrm{HSS}$ intravenously over $30 \mathrm{~min}$. As a result, hyponatremia in all diarrheic calves was significantly improved by the administration of $2.16 \%$ HSS from 122.2 $\pm 7.0 \mathrm{mEq} / /$ at pre to $134.8 \pm 3.7 \mathrm{mEq} / \mathrm{l}$ at post, which was above the threshold of $132 \mathrm{mEq} / \mathrm{l}$ for hyponatremia. Therefore, $2.16 \%$ HSS may be useful for hyponatremia in calves with diarrhea.

KEY WORDS: $2.16 \%$ hypertonic saline solution, calf, diarrhea, hyponatremia

Diarrhea remains the major problem and common cause of death in both beef and dairy calves [12, 18]. Although pathogens and failed feeding cause diarrhea in calves, its main effects are dehydration, metabolic acidosis, pre-renal uremia and hyponatremia [13]. It is widely accepted that intravenous (IV) fluid therapy is important for reducing the mortality associated with diarrhea in calves. Smith and Berchtold [23] recommended intravenously administering $5 l$ of physiological saline and $250 \mathrm{~m} l$ of $8.4 \%$ hypertonic sodium bicarbonate (total $66 \mathrm{~g}$ of $\mathrm{NaCl}$ ) to calves with diarrhea, dehydration and moderate to severe acidosis. Slower infusion rates of 30 to $50 \mathrm{ml} / \mathrm{kg} / \mathrm{hr}$ are often used to avoid overhydration and pulmonary edema in calf practice. Therefore, a $40-\mathrm{kg}$ calf with $10 \%$ dehydration requires 2.5 to $4 \mathrm{hr}$ to be rehydrated following the above regimen [23]. On the other hand, the administration of small volumes of hypertonic saline solutions (HSS) provides major advantages over large volumes of isotonic crystalloid solutions and has been recommended for diarrheic calves [10, 18, 30]. HSS are suitable for use in the field because they do not require intravenous catheterization or periodic monitoring. The benefits of HSS include the rapid increase in preload and transient decrease in afterload $[11,12]$. Commercially available HSS for treating calves have a concentration of $7.2 \%$ or $7.5 \%$. Many bovine practitioners and researchers $[10,17,24,30]$ began using $7.2 \%$ or $7.5 \%$ HSS to treat diarrheic calves after Constable et al. $[11,12]$ demonstrated the efficacy and safety of $7.5 \%$ HSS on the hemodynamic and biochemical parameters in an endotoxin shock model. Several studies $[6,10,18,28]$ suggested that the combination of a small amount of intravenous $7.2 \%$ HSS infusion and oral electrolyte solution rather than conventional isotonic crystalloid fluid improves dehydration and acid-base abnormalities in a shorter time in diarrheic calves with moderate dehydration and metabolic acidosis. However, Suzuki et al. [25] reported that the serum sodium $(\mathrm{Na})$ concentration increased to $157 \pm 3.5 \mathrm{mEq} / l$ when $7.2 \%$ HSS was administered intravenously to normovolemic heifers weighing $260 \pm 7.0 \mathrm{~kg}$ according to the manufacturer's recommendations in Japan ( $5 \mathrm{ml} / \mathrm{kg}$, over $15 \mathrm{~min})$. Hypernatremia is defined as an increase in the serum $\mathrm{Na}$ concentration to above $160 \mathrm{mEq} / \mathrm{l}$ [3] and is an uncommon complication in diarrheic calves $[3,13,28]$. In these rare cases, hypernatremia develops when excess Na-containing salts are ingested [1, 21]. The 3-fold dose of $7.2 \%$ HSS was reported to exceed the threshold of hypernatremia of $160 \mathrm{mEq} / l[25]$. Therefore, the development of adverse events due to rapid changes in the Na concentration should be carefully monitored when using HSS.

Recently, the United States [29] and Europe developed treatment guidelines [15, 24] for hyponatremia in humans. Severe 
symptoms are treated by $2-\mathrm{ml} / \mathrm{kg} \mathrm{3 \%}$ HSS bolus infusions irrespective of the duration of hyponatremia [20]. A 3\% hypertonic saline solution was demonstrated to be a safe infusion for correcting blood $\mathrm{Na}$ abnormalities and dehydration without significant adverse events or rapid hemodynamic changes [7, 19, 20, 22]. However, in some cases, even 3\% HSS administration causes hypernatremia in humans [5].

As severe hypernatremia is a serious condition associated with high mortality not only in humans [9], but also in calves [21, 28], less than 3\% HSS may be safer for the treatment of diarrheic calves with hyponatremia than $7.2 \%$ HSS, which causes rapid hemodynamic changes. There are many reports on the therapeutic effects of $7.2 \%$ or $7.5 \%$ HSS in diarrheic calves $[6,17,18,23$, $26,30]$, but to the best of our knowledge, there are no reports on the efficacy of less than $3 \%$ HSS. In addition, it is important to be able to dispense the solution easily in the field because the saline solutions commercially available are $0.9 \%$ and $7.2 \%$. Therefore, we formulated a commercially available $0.9 \%$ physiological saline solution and $7.2 \%$ HSS at a ratio of $4: 1$ to conveniently administer $2.16 \%$ HSS. In the present study, we examined whether $2.16 \%$ HSS, which can be easily prepared from commercially available $0.9 \%$ and $7.2 \%$ saline solution, can safely improve hyponatremia in calves with diarrhea.

This study was conducted for clinical purposes at commercial farms in the jurisdiction of the Hokushin Veterinary Medical Center, Nagano Prefectural Federation of the Agricultural Mutual Aid Association. Thirteen female Holstein calves, with a mean age of $21.4 \pm 10.9$ days old, exhibiting moderate diarrhea and depression were enrolled in the study. The clinical parameters posture, behavior, and palpebral reflex were closely correlated to base excess and d-lactate concentrations, respectively [27]. Especially, standing ability is important as a clinical finding of hyponatremia in calves [4]. In this study, thirteen calves were divided to mild ( $\mathrm{n}=6$ : stand unassisted), severe ( $\mathrm{n}=5$ : stand assisted) and critical groups ( $\mathrm{n}=2$ : inability to stand) depending on their ability to stand.

On the first consultation day, a 14-gauge catheter (Surflo ${ }^{\circledR}$ I.V. Catheter SR-OT1451C, Terumo Co., Tokyo, Japan) was implanted percutaneously into the right jugular vein for infusion of the $2.16 \%$ HSS. The $2.16 \%$ HSS was conveniently prepared by mixing $250 \mathrm{~m} l$ of commercially available 7.2\% HSS (Nihon Zenyaku Kogyo Co., Ltd., Fukushima, Japan) with $1 l$ of $0.9 \%$ physiological saline (Nihon Zenyaku Kogyo Co., Ltd). Eleven hyponatremic calves, except the two in the critical group, received 1,250 $\mathrm{m} l$ of $2.16 \%$ HSS over 15 min regardless of body weight (total $27 \mathrm{~g}$ of $\mathrm{NaCl}$ ). The remaining two calves in the critical group received $2,500 \mathrm{~m} l$ of $2.16 \%$ HSS intravenously over $30 \mathrm{~min}$ on the first consultation day (total $54 \mathrm{~g}$ of NaCl). In all calves, $20 \mathrm{mg} / \mathrm{kg}$ of cefazolin sodium (Cefazolin-injection, Fujita Pharmaceutical Co., Ltd., Tokyo, Japan) was added to 2.16\% HSS, but no other supportive therapy was given except oral electrolytes solution until after $24 \mathrm{hr}$. Commercial oral electrolytes solutions (Calf-right $\mathrm{S}$, Nihon Zenyaku Kogyo Co., Ltd.) were given twice per day between pre and post sampling.

Whole blood was collected from the jugular vein using a 1-m $l$ heparinized syringe before (pre) and on the day after fluid therapy (post). Immediately after blood sampling, blood $\mathrm{Na}$, potassium $(\mathrm{K})$, chloride $(\mathrm{Cl})$ and blood urea nitrogen (BUN) concentrations, and blood $\mathrm{pH}$ were measured using i-STAT200A and EC8+ cartridge (Abbott Lab. North Chicago, IL, USA). The measured blood $\mathrm{pH}$ was automatically corrected by rectal temperature. The serum total protein (TP) concentration was quantified by a refractometer method according to a standard method.

Statistical analyses were conducted using commercial statistical software (SPSS ${ }^{\circledR}$ Statistics version 25., Armonk, IBM Corp., NY, USA). Normally distributed data are reported as means \pm standard deviations (SD). The difference between pre and post values after $2.16 \%$ HSS administration in each calf was evaluated using the paired $t$-test. The difference between the mean values of each measured value in the mild and severe groups classified according to the standing ability was evaluated using the Student's $t$-test or Mann-Whitney $U$-test after assessing the variance. In addition, receiver operating characteristic (ROC) curves were used to characterize the sensitivity and specificity of each parameter related to the ability to stand in this study. Derived indexes of accuracy, in particular area under the curve (AUC) has a meaningful interpretation for disease classification from healthy subjects [14]. The optimal cut-off point was calculated using the Youden index [2]. The Youden index (J) is defined as the maximum vertical distance between the ROC curve and the diagonal or chance line, and is calculated as $\mathrm{J}=$ maximum [sensitivity + specificity-1]. The cut-off points on ROC curves that correspond to J were considered the optimal cut-off points [1]. The significance level was $P<0.05$.

According to human medical guidelines [15], hyponatremia is defined as a serum Na concentration of less than $136 \mathrm{mEq} / \mathrm{l}$ and that less than $125 \mathrm{mEq} / l$ is defined as "severe hyponatremia" by the United States guidelines [29], and as "marked hyponatremia" by the European guidelines $[15,24]$. In cattle, hyponatremia is defined as a serum Na concentration of less than $132 \mathrm{mEq} / \mathrm{l}$ and that less than $120 \mathrm{mEq} / l$ is defined as "severe hyponatremia" [4]. In this study, all calves were diagnosed with hyponatremia because their blood $\mathrm{Na}$ concentrations were less than $132 \mathrm{mEq} / \mathrm{l}$.

As a result of classification into mild and severe groups according to their standing ability, no significant differences were observed between the two groups in all measurement parameters except blood Na concentration. The blood Na concentration in calves in the severe group $(121.2 \pm 3.8 \mathrm{mEq} / l)$ was lower than that in the mild group $(127.2 \pm 4.2 \mathrm{mEq} / l, P=0.038)$. Based on ROC analysis, hyponatremic calves with blood Na concentrations of $<121 \mathrm{mEq} / l$ were diagnosed as "stand assisted" with $100 \%$ sensitivity and $80 \%$ specificity ( $\mathrm{AUC}=0.937, P=0.018$ ). In the calves with hyponatremia, the clinical findings associated with the ability to stand were consistent with the range of blood $\mathrm{Na}$ concentrations according to hyponatremia guidelines in humans [15, 24, 29]. Therefore, this study suggested that clinical findings related to the ability to stand can diagnose mild and severe hyponatremia. Statistical analysis was unable to be performed for comparison with the other groups because there were only two calves in the critical group aged both 30 days-old, but they were diagnosed with critical hyponatremia, hyperkalemia and hypochloremia because their blood $\mathrm{Na}, \mathrm{K}$ and $\mathrm{Cl}$ concentrations were $110.0 \pm 0.0,6.8 \pm 0.3$ and $75.5 \pm 3.2 \mathrm{mEq} / l$, respectively.

Of the 13 hyponatremic calves administered $2.16 \%$ HSS, one calf died of severe hypokalemia, but twelve had a good prognosis 
Table 1. Comparison of blood $\mathrm{Na}, \mathrm{K}$ and $\mathrm{Cl}$ concentrations immediately before and 24 -hr after $2.16 \%$ hypertonic saline solution (HSS) administration in diarrheal calves with hyponatremia

\begin{tabular}{lllcccc}
\hline Parameter & Unit & & Total $(\mathrm{n}=13)$ & Mild $(\mathrm{n}=6)$ & Severe $(\mathrm{n}=5)$ & Critacal $(\mathrm{n}=2)$ \\
\hline Age & days & & $21.4 \pm 10.9$ & $17.0 \pm 10.5$ & $22.2 \pm 11.2$ & 30 \\
$\mathrm{Na}^{+}$ & $\mathrm{mEq} / l$ & pre & $122.2 \pm 7.0$ & $127.2 \pm 4.2$ a) & $\left.121.2 \pm 3.8^{\mathrm{b}}\right)$ & $110.0 \pm 0.0$ \\
& & post & $134.8 \pm 3.7 * *$ & $134.7 \pm 3.8^{* *}$ & $133.4 \pm 3.4 * *$ & $139.0 \pm 0.0$ \\
$\mathrm{~K}^{+}$ & $\mathrm{mEq} / l$ & pre & $5.1 \pm 1.5$ & $4.8 \pm 1.4$ & $4.9 \pm 1.6$ & $6.8 \pm 0.3$ \\
& & post & $3.8 \pm 1.0 * *$ & $4.1 \pm 0.6 * *$ & $3.7 \pm 1.4 * *$ & $3.6 \pm 0.2$ \\
$\mathrm{Cl}^{-}$ & $\mathrm{mEq} / l$ & pre & $87.2 \pm 7.3$ & $90.7 \pm 6.3$ & $87.8 \pm 3.6$ & $75.5 \pm 3.2$ \\
& & post & $95.9 \pm 5.6 * *$ & $96.3 \pm 4.8 * *$ & $94.2 \pm 7.6 * *$ & $99.0 \pm 0.0$ \\
venous pH & 1 & pre & $7.357 \pm 0.034$ & $7.346 \pm 0.038$ & $7.363 \pm 0.033$ & $7.376 \pm 0.012$ \\
& & post & $7.388 \pm 0.031 *$ & $7.388 \pm 0.032 *$ & $7.392 \pm 0.035 *$ & $7.375 \pm 0.013$ \\
Total Protein (TP) & $\mathrm{g} / \mathrm{d} l$ & pre & $5.9 \pm 0.8$ & $6.0 \pm 0.8$ & $5.9 \pm 1.4$ & $5.9 \pm 0.4$ \\
& & post & $6.0 \pm 1.7$ & $5.9 \pm 1.5$ & $6.7 \pm 3.0$ & $5.3 \pm 0.2$ \\
Blood Urea Nitrogen & $\mathrm{mg} / \mathrm{d} l$ & pre & $28.5 \pm 22.9$ & $18.3 \pm 10.1$ & $23.0 \pm 15.6$ & $72.6 \pm 6.6$ \\
(BUN) & & post & $16.3 \pm 13.5 *$ & $11.3 \pm 6.4 *$ & $13.2 \pm 11.3 *$ & $39.1 \pm 7.7$ \\
\hline
\end{tabular}

Mild (stand unassisted), Severe (stand assisted) and Critical groups (inability to stand) depending on their ability to stand. Pre vs. Post; $* P<0.05, * * P<0.01$ by paired $t$-test. Mild vs. severe; a) vs. b) $P=0.038$ by Student's $t$-test. Statistical analysis was not performed in the Critical group due to only two animals.

and were cured (cure rate=92.3\%). A died calf whose serum potassium concentration was $4.4 \mathrm{mEq} / \mathrm{l}$ at pre presented hypokalemia of $1.9 \mathrm{mEq} / \mathrm{l}$ on the day after administration. The changes in blood $\mathrm{Na}, \mathrm{K}$ and $\mathrm{Cl}$ concentrations in the diarrheic calves with hyponatremia that received $2.16 \%$ HSS are shown in Table 1 . The administration of $2.16 \%$ HSS significantly increased the blood $\mathrm{Na}(P<0.01)$ and $\mathrm{Cl}$ concentrations $(P<0.01)$, and reduced the blood $\mathrm{K}(P<0.01)$ and BUN concentrations $(P<0.05)$ in hyponatremic calves. In particular, the concentrations of blood $\mathrm{Na}$ in all diarrheic calves, including dead calves, were significantly increased by the administration of $2.16 \%$ HSS from $122.2 \pm 7.0 \mathrm{mEq} / l$ at pre to $134.8 \pm 3.7 \mathrm{mEq} / \mathrm{l}$ at post, which was above the threshold of $132 \mathrm{mEq} / l$ for hyponatremia. Although Blood Na concentrations of $1(128 \mathrm{mEq} / l)$ and 2 calves (both $130 \mathrm{mEq} / l)$ in the mild and severe groups, respectively, were not exceed $132 \mathrm{mEq} / \mathrm{l}$ at $24 \mathrm{hr}$ after giving a $2.16 \% \mathrm{HSS}$, all hyponatremia calves except $1 \mathrm{died}$ calf could stand themselves. Our study demonstrated that intravenous administration of $2.16 \% \mathrm{HSS}$ is useful to correct the Na concentration in diarrheic calves with hyponatremia. On the other hand, in a dead hyponatremic calf aged 14 days-old in the severe group, the blood $\mathrm{Na}$ and $\mathrm{Cl}$ concentrations were low at 119.0 and $87.0 \mathrm{mEq} / \mathrm{l}$, respectively, but the $\mathrm{K}$ concentration was normal at $4.4 \mathrm{mEq} / l$ on the first consultation day. After the administration of $2.16 \%$ HSS, the blood Na concentration recovered to 138.0 $\mathrm{mEq} / l$, but the blood $\mathrm{K}$ concentration was $1.9 \mathrm{mEq} / l$, which resulted in severe hypokalemia. At the sampling the day after $2.16 \%$ HSS was administered (post), the calf presented an inability of standing and a severely depressed and died several hours after sampling. Jafari et al. [16] reported hypokalemia as the most frequent adverse event of HSS in human randomized clinical trials. A sudden increase in the circulating plasma volume with an osmotic pressure gradient causes a decrease in the blood component concentration due to the significant dilution of plasma. A rapid increase in the extracellular $\mathrm{Na}$ concentration does not induce a rapid decrease in the extracellular K concentration due to the exchange of extracellular Na with intracellular K [16]. However, one calf who died may have had a low total $\mathrm{K}$ content due to chronic diarrhea, resulting in hypokalemia. Therefore, it may be necessary to pay attention to chronic or acute diarrhea when using $2.16 \%$ HSS for diarrheic calves with hyponatremia. One calf that died became comatose during the administration of $2.16 \%$ HSS. However, no clinical signs, such as arrhythmia, jugular distension, pulmonary edema or collapse, were observed in all animals except the dead calf during and after the administration of $2.16 \%$ HSS. This clinical study is limited by the lack of positive and negative controls. Further studies will need to compare the safety and efficacy of $2.16 \%$-HSS to controls receiving general fluid therapy with isotonic polyelectrolyte fluids with or without bicarbonate. In addition, further studies are necessary to assess of optimal administration rate of $2.16 \% \mathrm{HSS}$ for dehydrated calves. Berchtold [8] suggested that a maximum rate of $80 \mathrm{ml} / \mathrm{kg} / \mathrm{hr}$ for intravenously (iv) fluid administration has been used without inducing significant overhydration and hypertension. This rate was equivalent to a maximum fluid volume of $4.0 \mathrm{l}$ for a $50 \mathrm{~kg}$ severely dehydrated calf. In this study, no adverse effects due to fluid therapy such as overhydration, hypertension and pulmonary edema were observed during and immediately after administration of HSS, but the infusion rate was $100 \mathrm{~m} / \mathrm{kg} / \mathrm{hr}$ that was faster than the maximum rate shown by Berchtold [8].

In conclusion, clinical findings can estimate the severity of hyponatremia due to the correlation between the blood Na concentration and standing ability. This study demonstrated that $2.16 \%$ HSS can be easily prepared by adding $250 \mathrm{~m} l$ of commercially available $7.2 \%$ HSS to $1 l$ of commercially available $0.9 \%$ saline solution, and can improve hyponatremia in calves with diarrhea. Since the treatment of hyponatremia using $2.16 \% \mathrm{HSS}$ can be performed in about 15 to $30 \mathrm{~min}$, it is more time, labor, and economically advantageous than traditional fluid therapy using isotonic saline. In addition, since $2.6 \%$ HSS has a lower Na concentration in the formulation than $7.2 \% \mathrm{HSS}$, it is considered to be safer in calves with less developed renal and heart functions than mature cattle. Although the side effects of hypokalemia should be taken into consideration when administering $2.16 \%$ HSS, it was suggested to be a convenient and useful mildly hypertonic solution for the intravenously treatment of diarrheic calves with hyponatremia. 
CONFLICTS OF INTEREST. There are no conflicts of interest regarding this study.

ACKNOWLEDGMENT. All authors would like to express their gratitude to Dr. Sononaka for his great support.

\section{REFERENCES}

1. Abutarbush, S. M. and Petrie, L. 2007. Treatment of hypernatremia in neonatal calves with diarrhea. Can. Vet. J. 48: 184-187. [Medline]

2. Akobeng, A. K. 2007. Understanding diagnostic tests 3: Receiver operating characteristic curves. Acta Paediatr. 96: 644-647. [Medline] [CrossRef]

3. Angelos, S. M., Smith, B. P., George, L. W., House, J. K., Van Metre, D. C., Fecteau, G., Thacker, V. C. and Angelos, J. A. 1999. Treatment of hypernatremia in an acidotic neonatal calf. J. Am. Vet. Med. Assoc. 214: 1364-1367, 1335. [Medline]

4. Angelos, S. M. and Van Metre, D. C. 1999. Treatment of sodium balance disorders. Water intoxication and salt toxicity. Vet. Clin. North Am. Food Anim. Pract. 15: 587-607, vii. [Medline] [CrossRef]

5. Arambewela, M. H., Somasundaram, N. P. and Garusinghe, C. 2016. Extreme hypernatremia as a probable cause of fatal arrhythmia: a case report. J. Med. Case Reports 10: 272. [Medline] [CrossRef]

6. Aydogdu, U., Yildiz, R., Guzelbektes, H., Naseri, A., Akyuz, E. and Sen, I. 2018. Effect of combinations of intravenous small-volume hypertonic sodium chloride, acetate Ringer, sodium bicarbonate, and lactate Ringer solutions along with oral fluid on the treatment of calf diarrhea. Pol. J. Vet. Sci. 21: 273-280. [Medline]

7. Ayus, J. C. and Moritz, M. L. 2019. Misconceptions and barriers to the use of hypertonic saline to treat hyponatremic encephalopathy. Front. Med. (Lausanne) 6: 47. [Medline] [CrossRef]

8. Berchtold, J. 2009. Treatment of calf diarrhea: intravenous fluid therapy. Vet. Clin. North Am. Food Anim. Pract. 25: 73-99, vi. [Medline] [CrossRef]

9. Braun, M. M., Barstow, C. H. and Pyzocha, N. J. 2015. Diagnosis and management of sodium disorders: hyponatremia and hypernatremia. Am. Fam. Physician 91: 299-307. [Medline]

10. Constable, P. D., Gohar, H. M., Morin, D. E. and Thurmon, J. C. 1996. Use of hypertonic saline-dextran solution to resuscitate hypovolemic calves with diarrhea. Am. J. Vet. Res. 57: 97-104. [Medline]

11. Constable, P. D., Schmall, L. M., Muir, W. W. 3rd., Hoffsis, G. F. and Shertel, E. R. 1991. Hemodynamic response of endotoxemic calves to treatment with small-volume hypertonic saline solution. Am. J. Vet. Res. 52: 981-989. [Medline]

12. Constable, P. D., Schmall, L. M., Muir, W. W. 3rd. and Hoffsis, G. F. 1991. Respiratory, renal, hematologic, and serum biochemical effects of hypertonic saline solution in endotoxemic calves. Am. J. Vet. Res. 52: 990-998. [Medline]

13. Groutides, C. P. and Michell, A. R. 1990. Changes in plasma composition in calves surviving or dying from diarrhoea. Br. Vet. J. 146: 205-210. [Medline] [CrossRef]

14. Hajian-Tilaki, K. 2013. Receiver operating characteristic (ROC) curve analusis for medical diagnostic test evaluation. Caspian J. Intern. Med. 4: 627-635. [Medline]

15. Hoorn, E. J. and Zietse, R. 2017. Diagnosis and treatment of hyponatremia: Compilation of the guidelines. J. Am. Soc. Nephrol. 28: $1340-1349$. [Medline] [CrossRef]

16. Jafari, M., Ala, S., Haddadi, K., Alipour, A., Mojtahedzadeh, M., Ehteshami, S., Abediankenari, S., Shafizad, M., Salehifar, E. and Khalili, F. 2018. Cotreatment with furosemide and hypertonic saline decreases serum neutrophil gelatinase-associated lipocalin (NGAL) and serum creatinine concentrations in traumatic brain injury: A randomized, single-blind clinical trial. Iran. J. Pharm. Res. 17: 1130-1140. [Medline]

17. Koch, A. and Kaske, M. 2008. Clinical efficacy of intravenous hypertonic saline solution or hypertonic bicarbonate solution in the treatment of inappetent calves with neonatal diarrhea. J. Vet. Intern. Med. 22: 202-211. [Medline] [CrossRef]

18. Leal, M. L., Fialho, S. S., Cyrillo, F. C., Bertagnon, H. G., Ortolani, E. L. and Benesi, F. J. 2012. Intravenous hypertonic saline solution (7.5\%) and oral electrolytes to treat of calves with noninfectious diarrhea and metabolic acidosis. J. Vet. Intern. Med. 26: 1042-1050. [Medline] [CrossRef]

19. Mesghali, E., Fitter, S., Bahjri, K. and Moussavi, K. 2019. Safety of peripheral line administration of $3 \%$ hypertonic saline and mannitol in the emergency department. J. Emerg. Med. 56: 431-436. [Medline] [CrossRef]

20. Overgaard-Steensen, C. and Ring, T. 2013. Clinical review: practical approach to hyponatraemia and hypernatraemia in critically ill patients. Crit. Care 17: 206. [Medline] [CrossRef]

21. Pringle, J. K. and Berthiaume, L. M. 1988. Hypernatremia in calves. J. Vet. Intern. Med. 2: 66-70. [Medline] [CrossRef]

22. Smart, L., Macdonald, S. P. J., Bosio, E., Fatovich, D., Neil, C. and Arendts, G. 2019. Bolus therapy with $3 \%$ hypertonic saline or $0.9 \%$ saline in emergency department patients with suspected sepsis: A pilot randomised controlled trial. J. Crit. Care 52: 33-39. [Medline] [CrossRef]

23. Smith, G. W. and Berchtold, J. 2014. Fluid therapy in calves. Vet. Clin. North Am. Food Anim. Pract. 30: 409-427, vi. [Medline] [CrossRef]

24. Spasovski, G., Vanholder, R., Allolio, B., Annane, D., Ball, S., Bichet, D., Decaux, G., Fenske, W., Hoorn, E. J., Ichai, C., Joannidis, M., Soupart, A., Zietse, R., Haller, M., van der Veer, S., Van Biesen, W., Nagler E., Hyponatraemia Guideline Development Group. 2014. Clinical practice guideline on diagnosis and treatment of hyponatraemia. Nephrol. Dial. Transplant. 29 Suppl 2: i1-i39. [Medline] [CrossRef]

25. Suzuki, K., Ajito, T. and Iwabuchi, S. 1998. Effect of a 7.2\% hypertonic saline solution infusion on arterial blood pressure, serum sodium concentration and osmotic pressure in normovolemic heifers. J. Vet. Med. Sci. 60: 799-803. [Medline] [CrossRef]

26. Suzuki, K., Suzuki, T., Miyahara, M., Iwabuchi, S. and Asano, R. 2005. Comparison of a small volume of hypertonic saline solution and dextran 40 on hemodynamic alternations in conscious calves. J. Vet. Sci. 6: 111-116. [Medline] [CrossRef]

27. Trefz, F. M., Lorch, A., Feist, M., Sauter-Louis, C. and Lorenz, I. 2012. Metabolic acidosis in neonatal calf diarrhea-clinical findings and theoretical assessment of a simple treatment protocol. J. Vet. Intern. Med. 26: 162-170. [Medline] [CrossRef]

28. Trefz, F. M., Lorenz, I., Lorch, A. and Constable, P. D. 2017. Clinical signs, profound acidemia, hypoglycemia, and hypernatremia are predictive of mortality in 1,400 critically ill neonatal calves with diarrhea. PLoS One 12: e0182938. [Medline] [CrossRef]

29. Verbalis, J. G., Goldsmith, S. R., Greenberg, A., Korzelius, C., Schrier, R. W., Sterns, R. H. and Thompson, C. J. 2013. Diagnosis, evaluation, and treatment of hyponatremia: expert panel recommendations. Am. J. Med. 126 Suppl 1: S1-S42. [Medline] [CrossRef]

30. Walker, P. G., Constable, P. D., Morin, D. E., Foreman, J. H., Drackley, J. K. and Thurmon, J. C. 1998. Comparison of hypertonic saline-dextran solution and lactated Ringer's solution for resuscitating severely dehydrated calves with diarrhea. J. Am. Vet. Med. Assoc. 213: 113-121. [Medline] 